\title{
Strengthening the Drug Supply Chain Management in a tertiary care hospital in Sri Lanka
}

\author{
Ranasinghe $\mathrm{GSP}^{I^{*}}$, Panapitiya $\mathrm{PWC}^{2}$, Samarage $\mathrm{SM}^{3}$ \\ Acting Consultant in Medical Administration, Ministry of Health Sri Lanka \\ Deputy Director General Medical Services I, Ministry of Health Sri Lanka \\ Senior Fellow, Institute for Health Policy Sri Lanka \\ * First Author
}

DOI: 10.29322/IJSRP.11.06.2021.p11406

http://dx.doi.org/10.29322/IJSRP.11.06.2021.p11406

\begin{abstract}
Background

Supply Chain Management is a process which creates a product or a service from raw materials to a final product that is consumed. It is a life cycle processes involving physical goods, information, and financial flows occurs both in forward and backward directions with the objective to satisfy end consumer requisites with goods and services from diverse, connected suppliers. Drugs are an essential component for running the health care institutions at National and Provincial levels, therefore effective Drug Supply Chain Management is vital in the health sector. Sri Lankan public health sector divided in to line ministry and provincial ministry health care institutions, which drugs are received through Medical Supply Division (MSD) and Regional Medical Supply Division (RMSD) respectively. Medical Supply Division (MSD) is the focal point for supplying of drugs throughout the country. The pharmacists play a major role in Drugs Supply Chain Management, and the knowledge gap affects Medical Supply Chain Management.
\end{abstract}

Purpose

The objective of this study was to strengthen the Drug Supply Chain Management, through an intervention of improving the knowledge and attitudes on Drug Supply Chain Management among Pharmacists, in the Colombo South Teaching Hospital.

\section{Methodology}

This was a quasi-experimental study carried out in three phases. In phases I and III, Key Informant Interviews and Focus Group Discussions were conducted to gather qualitative data, while a questionnaire and a checklist were used to gather quantitative data. Interventions were carried out in phase II which includedonsite and online training and supervision. Evaluation of effectiveness of the intervention was done in phase III.

\section{Results and Discussion}

Results showed that monthly estimation of drugs, forecasting the drugs requirement, calculating the annual drugs requirement, ordering the drugs, receiving the drugs, quality checks, dispensing, keeping inventories and record keeping, handling the medical supply management information system were satisfactory, both before and after the intervention. But the Store management, internal distribution to wards and units, and local purchase of drugs were unsatisfactory, and improved after the intervention. The overall pharmacists knowledge on Supply Chain Management, improved significantly $(\mathrm{p}<0.001)$ in the post intervention compared to pre intervention. The overall pharmacists attitudes significantly improved in the post intervention compared to pre intervention at $\mathrm{p}<$ 0.001 level. Inward and units drugs supply services improved in the post intervention compared to pre intervention at $\mathrm{p}$ values 
ranging from $\mathrm{p}<0.001$ to 0.002 . Patient satisfaction and percentage of drugs received by patients also significantly improved in post intervention compared to pre intervention at $\mathrm{p}<0.001$ significance level. Selected key domains on store management showed that there was a clear improvement in post intervention compared to pre intervention.

\section{Conclusion}

Improving the Knowledge and Attitudes on Drug Supply Chain Management among Pharmacists is an effective intervention to strengthen the Drug Supply Chain Management at Institutional Level.

Key Words: Drugs Supply Chain Management, Pharmacists, Knowledge, Attitudes, Interventions

\section{INTRODUCTION}

Supply Chain Management (SCM) is a process which creates a product or a service from raw materials to final product that is consumed by the consumer. In this process the product, information and the finance flow occur both in forward and backward directions and also satisfy end consumer requisites with goods and services from diverse, connected suppliers (1), (2) Drugs are an essential component for running the health care institutions at National and Provincial levels of the country. Drugs SCM is vital for health care institutions. The management of drug supply is organized under five basic functions, namely the selection, quantification, procurement, distribution, and use (3). Core management supporting systems includes organization, sustainability, financing, managing information, human resource management and quality assurance management (3). The success of drug management cycle in the health care institutions will depend upon the ability to reliably and consistently supply the standard quality medicines at affordable rates to health care facilities at all the levels of healthcare system (4).

In Sri Lanka, public health sector is mainly divided to line ministry and provincial ministry health care institutions, which receive drugs through the Medical Supply Division (MSD) centrally and Regional Medical Supply Divisions (RMSD) regionally respectively. Medical Supply Division (MSD) is the focal point for selection, estimation, procuring, quality control and supplying of drugs throughout the country (5). The pharmacists play a major role in Drugs SCM (6). Continuous supply of medicine is essential for patient management and prevention of diseases and deaths at health care institutions and Drugs SCM is vital at the country level and institutional level. The total line Ministry expenditure (capital and recurrent) for 2016 was 134.78 billion Sri Lankan rupees and out of that expenditure (28.2\%), the annual expenditure for the MSD is 38 Billion Rupees for year 2016 (5). To provide quality health care services Medical products and Drugs are essential, and should be available at right place, at right time, with right quality, and right quantity, at a right cost, in the health care institutions. To achieve this all the relevant staff involved in this process should have a sound knowledge regarding the SCM and skills of handling SCM. Pharmacists are the main contributors to this Medical Drugs SCM at MSD, RMSD and Health Care Institutional level (5). Pharmacists play a key role in Drugs SCM and the knowledge gap affects Medical Drug SCM (6), (7), (8), (9). Regular training of health care staff with knowledge on modernized store and inventory management practices is vital (10).

The objective of this study was "To strengthen the Drug Supply Chain Management, through an intervention of improving the Knowledge and Attitude on Drug Supply Chain Management among Pharmacists, in Colombo South Teaching Hospital a tertiary care hospital"

\section{METHODOLOGY}


This was a quasi-experimental research project carried out in three phases, namely phase I, II and III.

Study setting was the Colombo South Teaching Hospital (CSTH), which is a tertiary care hospital with all four major specialties and minor specialties with a bed strength of 1110 and the study period was 12 months.

The study sample comprised of Director CSTH (1), Chief Pharmacist CSTH (1), all other pharmacists at CSTH (37), thirty-three in number of ward and units in-charge of CSTH (33) and a sample of sixty-one (61) randomly patients.

Three questionnaires and one check list were developed according to the literature review and expert opinion. Face validity and content validity was done. Questionnaires were pre-tested in another setting and modified questionnaires and check list were used for the study. Qualitative data was gathered by Key Informant Interviews from the Director and Chief Pharmacists of the Hospital and also by Focus Group Discussions with a randomly selected Pharmacists of the Hospital in phase I (Pre-intervention) and phase III (Post-intervention).

Qualitative data on key areas were summarized and documented. Quantitative data was analyzed by using the Statistical Package for the Social Sciences (SPSS) Data analyzing software. Appropriate statistical test was done to assess the significance of the pre and the post results after the intervention in the quantitative analysis.

In the Phase I, a situational analysis was done to identify the deficiencies in Drug Supply Chain Management (SCM), related to the Pharmacists in Colombo South Teaching Hospital (CSTH), the knowledge on SCM and attitudes among the Pharmacists, inward and unit supply of drugs, patient satisfaction at the clinic Outdoor Patient Department (OPD) pharmacy and percentage of drugs received by patients out of prescribed drugs, through a descriptive and analytic cross-sectional study. Phase II was the intervention and phase III was the post interventional assessment. To assess the situational and gaps in phase I and post intervention in phase III, qualitative and quantitative techniques were used. Qualitative data was gathered by Key Informant Interviews (KIII) and Focus Group Discussions (FGD). Quantitative data was gathered using Questionnaires and check lists. Questionnaires were used to assess the Knowledge and Attitude among pharmacists, satisfaction survey on wards and units in-charges, and to survey the medical clinic patients (an interviewer administered Questionnaire). To assess the store management, observation was done on selected key domains using a check list. In phase II the designing and implementing the intervention was done. It included, curriculum development for institutional and online training, institutional workshops for pharmacists at the CSTH to build the capacity on Drugs SCM and Attitudes based on the curriculum prepared, one to one education and supervision on Drugs SCM and Attitudes, steps to educate the head of the institute on gaps found and motivated to improve gaps, field visit to observe best practices for the stakeholders and also implementation of the on-line training programme developed on Drug SCM, Attitudes, leadership and Motivation.

Phase III was the post intervention phase, and the same study instruments in the phase I were used to evaluate the post interventional results.

Ethical clearance was obtained for the study and administrative clearance was taken from relevant authorities. Consent was taken from the pharmacists selected for the study and also from the volunteered patients at the clinic Outdoor Patient Department (OPD) pharmacy who came to collect the prescribed drugs from the clinic. 


\section{RESULTS AND DISCUSSION}

\section{Socio-Demographic factors}

The age of the pharmacists ranged from 24 years to 54 years with a mean age of 35 years and majority (68.4\%) were females.

Majority of the pharmacists (25) had Diploma, 3 had both Diploma and BSc and only one had the MSc in Pharmacy. There were 27 pharmacists, 10 intern pharmacists and 1 chief pharmacist.

Table 1 - Distribution of pharmacists according to place of work

\begin{tabular}{lrr}
\hline Work place & Frequency & Percent \\
\hline Consumables / Surgical & 4 & 10.5 \\
Drugs stores & 4 & 10.5 \\
Indoor Pharmacy & 6 & 15.8 \\
Office & 1 & 2.6 \\
Out Door Pharmacy / Clinic & 31.6 \\
Out Door Pharmacy / general OPD & 11 & $\mathbf{2 8 . 9}$ \\
\hline Total & $\mathbf{3 8}$ & $\mathbf{1 0 0 . 0}$ \\
\hline
\end{tabular}

Majority (23) pharmacists were in the Out Door Pharmacies namely clinic (12) and general OPD (11) (Table 1). Majority of pharmacists (24) had more than 1 year of experience. Out of 24, 18 had more than 6 years of experience. Mean experience was 9.3 years and the experience ranged from 3 months to 31 years of experience.

\section{Perception of the Director and Chief Pharmacist CSTH in Pre and Post intervention phases (by Key Information Interview)}

Both agreed that there was a knowledge gap in pharmacists and needed a capacity building programmes and training. KII revealed that, monthly estimation of drugs, forecasting the drugs requirement, calculating the annual drugs requirement, ordering the drugs, receiving the drugs, quality checks, dispensing, keeping inventories and record keeping, handling the Medical Supply Management Information System (MSMIS) an electronic database, were satisfactory both in before and after the intervention. Store management, internal distribution to wards and units, and local purchase of drugs were unsatisfactory before intervention and it was satisfactory after the intervention. Both commented that they perceived there was an improvement in knowledge and Drug SCM after the intervention.

\section{Focus Group Discussion with pharmacists (Pre and Post intervention)}

In the pre intervention FGD, main areas concerned among the pharmacists were, inadequate space in stores, heavy work load and lack of knowledge in SCM and non-availability of any capacity building programmes for them. In the post interventional FGD revealed that they had good capacity building programmes which helped to motivate them-selves, improve their knowledge on SCM and relevant areas. This improved knowledge was helpful for them to improve their work performance, coping with heavy work load, do their work efficiently and effectively, use of limited space appropriately and they were very satisfied.

\section{Knowledge and Attitude}

There was a significant improvement, in knowledge on SCM and knowledge on MSMIS (p < 0.001) when taken as separately and the overall Knowledge of Drugs SCM (SCM+MSMIS) was also improved post intervention at p < 0.001 significance level (Table 2). A questionnaire was developed to assess the knowledge on SCM and MSMIS system which contained key questions on SCM and MSMIS system. This questionnaire was given to pharmacists and evaluated the total score (converted given as out of 100) obtained by individual and taken the means before and after the interventions (Table 2). A significant improvement in attitude 
among Pharmacists was seen after the intervention compared to pre intervention $(\mathrm{p}<0.001)$. The attitudes were measured using a Likert Scale and the values ranged from 1 (Very poor attitude) to 5 (Very good attitudes). The mean value improved from 3.20 to 4.29 at $\mathrm{p}<0.001$ significance level after the intervention (Table 3 ).

\section{Outcome measurement of staff satisfaction on inward and units drugs distribution}

Inwards and Units in-charges survey and overall satisfaction level of pre and post intervention was done to assess effectiveness of the intervention. The measurements were satisfactory levels of the ward and unit in charges ranged from 1 (Highly Unsatisfactory) to 5 (Highly Satisfactory). Delays in receiving drugs during last month, out of stock of drugs during last month has improve significantly at $\mathrm{p}<0.001$ level and delays in Local Purchase has improved significantly at $\mathrm{p}=0.002$ significance level. The overall satisfaction on drugs supply among the inward and units in charges improved $p<0.001$ significance level after the intervention (table 4). This reflect that there is a significant improvement in inward and units distribution / supply of drugs in the institute after the intervention. To assess the internal distribution above proxy indicators were used (Any delays in receiving drugs during last month, any out of stock of drugs during last month, any delays in local purchase, overall satisfaction regarding drug supply to the ward / unit). 
an on total pharmacists before and after the intervention

Table 2 - Comparison of overall Knowledge of pharmacists on Drug SCM (SCM+MSMIS) according to place of work and on total pharmacists before and after th

\begin{tabular}{|c|c|c|c|c|c|c|c|c|c|c|c|c|}
\hline \multirow[t]{2}{*}{ Working category } & \multirow[t]{2}{*}{$\mathbf{n}$} & \multicolumn{5}{|c|}{ Pre } & \multicolumn{5}{|c|}{ Post } & \multirow{2}{*}{$\begin{array}{l}\text { Significance } \\
(\text { z-test , p)* }\end{array}$} \\
\hline & & Mean & SD & Median & Min & Max & Mean & SD & Median & Min & Max & \\
\hline Drugs stores & 4 & 55.35 & 9.41 & 57.92 & 42.50 & 63.06 & 81.39 & 4.72 & 82.22 & 75.00 & 86.11 & $\mathrm{Z}=1.826, \mathrm{p}=0.068^{* *}$ \\
\hline Out Door Pharmacy / Clinic & 12 & 48.45 & 16.54 & 51.81 & 6.94 & 73.06 & 76.46 & 9.69 & 80.69 & 54.17 & 86.11 & $\mathrm{Z}=3.059, \mathrm{p}=0.002$ \\
\hline Indoor Pharmacy & 6 & 58.75 & 10.44 & 59.58 & 39.72 & 69.72 & 85.37 & 6.99 & 85.56 & 73.61 & 93.06 & $\mathrm{Z}=2.201, \mathrm{p}=0.028$ \\
\hline Out Door Pharmacy / OPD & 11 & 57.60 & 10.91 & 58.33 & 31.11 & 70.56 & 80.63 & 11.05 & 82.78 & 51.39 & 94.44 & $\mathrm{Z}=2.934, \mathrm{p}=0.003$ \\
\hline Consumables/office & 5 & 57.39 & 4.29 & 56.11 & 53.06 & 64.17 & 83.89 & 4.12 & 83.33 & 79.17 & 90.28 & $\mathrm{Z}=2.023, \mathrm{p}=0.043$ \\
\hline Total & 38 & 54.63 & 12.50 & 55.97 & 6.94 & 73.06 & 80.57 & 9.05 & 82.08 & 51.39 & 94.44 & $\mathrm{Z}=5.374, \mathrm{p}<0.001$ \\
\hline
\end{tabular}

*Wilcoxon Signed Ranks Test was applied ** Sample is not adequate for the statistical test.

Table 3 - Comparison of Attitude of pharmacists according to place of work and on total pharmacists before and after the intervention

\begin{tabular}{|c|c|c|c|c|c|c|c|c|c|c|c|c|}
\hline \multirow{2}{*}{ Working category } & \multirow[t]{2}{*}{$\mathbf{n}$} & \multicolumn{5}{|c|}{ Pre } & \multicolumn{5}{|c|}{ Post } & \multirow{2}{*}{$\begin{array}{l}\text { Significance } \\
(z-t e s t, p) *\end{array}$} \\
\hline & & Mean & SD & Median & Min & $\operatorname{Max}$ & Mean & SD & Median & Min & Max & \\
\hline Drugs stores & 4 & 3.32 & 0.27 & 3.32 & 3.00 & 3.63 & 4.24 & 0.20 & 4.15 & 4.13 & 4.53 & $\mathrm{Z}=1.84, \mathrm{p}=0.066^{* *}$ \\
\hline Out Door Pharmacy / Clinic & 12 & 3.16 & 0.34 & 3.33 & 2.30 & 3.43 & 4.25 & 0.33 & 4.28 & 3.77 & 4.67 & $\mathrm{Z}=3.06, \mathrm{p}=0.002$ \\
\hline
\end{tabular}


International Journal of Scientific and Research Publications, Volume 11, Issue 6, June 2021

28

Indoor Pharmacy

$\begin{array}{ll}6 & 3.02\end{array}$

0.94

$3.42 \quad 1.13 \quad 3.60$

4.41

0.39

4.45

3.80

4.80

$\mathrm{Z}=2.20, \mathrm{p}=0.028$

Out Door Pharmacy / OPD

11

$3.33 \quad 0.23$

$\begin{array}{lll}3.40 & 2.90 \quad 3.63\end{array}$

4.30

0.22

4.23

3.97

4.70

$\mathrm{Z}=2.94, \mathrm{p}=0.003$

Consumables/office

$5 \quad 3.15$

0.10

$\begin{array}{lll}3.10 & 3.03 \quad 3.30\end{array}$

4.29

0.06

4.33

4.20

4.33

$\mathrm{Z}=2.06, \mathrm{p}=0.039$

Total 38

3.20

0.43

$\begin{array}{lll}3.32 & 1.13 & 3.63\end{array}$

4.29

0.27

4.30

3.77

4.80

$\mathrm{Z}=5.38, \mathrm{p}<0.001$

*Wilcoxon Signed Ranks Test was applied, ** Sample is not adequate for the statistical test. 
Table 4 - In-ward and Unit In-charge survey data before and after the intervention

\begin{tabular}{|c|c|c|c|c|c|c|c|c|c|c|c|}
\hline \multirow{2}{*}{ Statement } & \multicolumn{5}{|c|}{ Pre $(n=33)$} & \multicolumn{5}{|c|}{ Post $(n=33)$} & \multirow{2}{*}{$\frac{\text { Significance }^{* *}}{(\mathrm{z} \text {-value, } \mathrm{p})}$} \\
\hline & Mean & SD & Median & Min & Max & Mean & SD & Median & Min & Max & \\
\hline $\begin{array}{l}\text { Any out of stock of drugs } \\
\text { during last month }\end{array}$ & 2.30 & 1.29 & 2.00 & 1.00 & 5.00 & 3.64 & 1.17 & 4.00 & 1.00 & 5.00 & $Z=3.57, p<0.001$ \\
\hline Any delays in local purchase & 2.39 & 1.22 & 2.00 & 1.00 & 5.00 & 3.52 & 1.23 & 4.00 & 1.00 & 5.00 & $\mathrm{Z}=3.12, \mathrm{p}=0.002$ \\
\hline Overall satisfaction & & & & & & & & & & & \\
\hline regarding drug supply to the & 3.15 & 0.83 & 3.00 & 2.00 & 5.00 & 4.27 & 0.72 & 4.00 & 2.00 & 5.00 & $\mathrm{Z}=4.28, \mathrm{p}<0.001$ \\
\hline Ward / Unit & & & & & & & & & & & \\
\hline
\end{tabular}

**Wilcoxon Signed Ranks Test was used for significance 
Outcome measurement at the clinic OPD level

Table 5 - Degree of patients education before and after the intervention

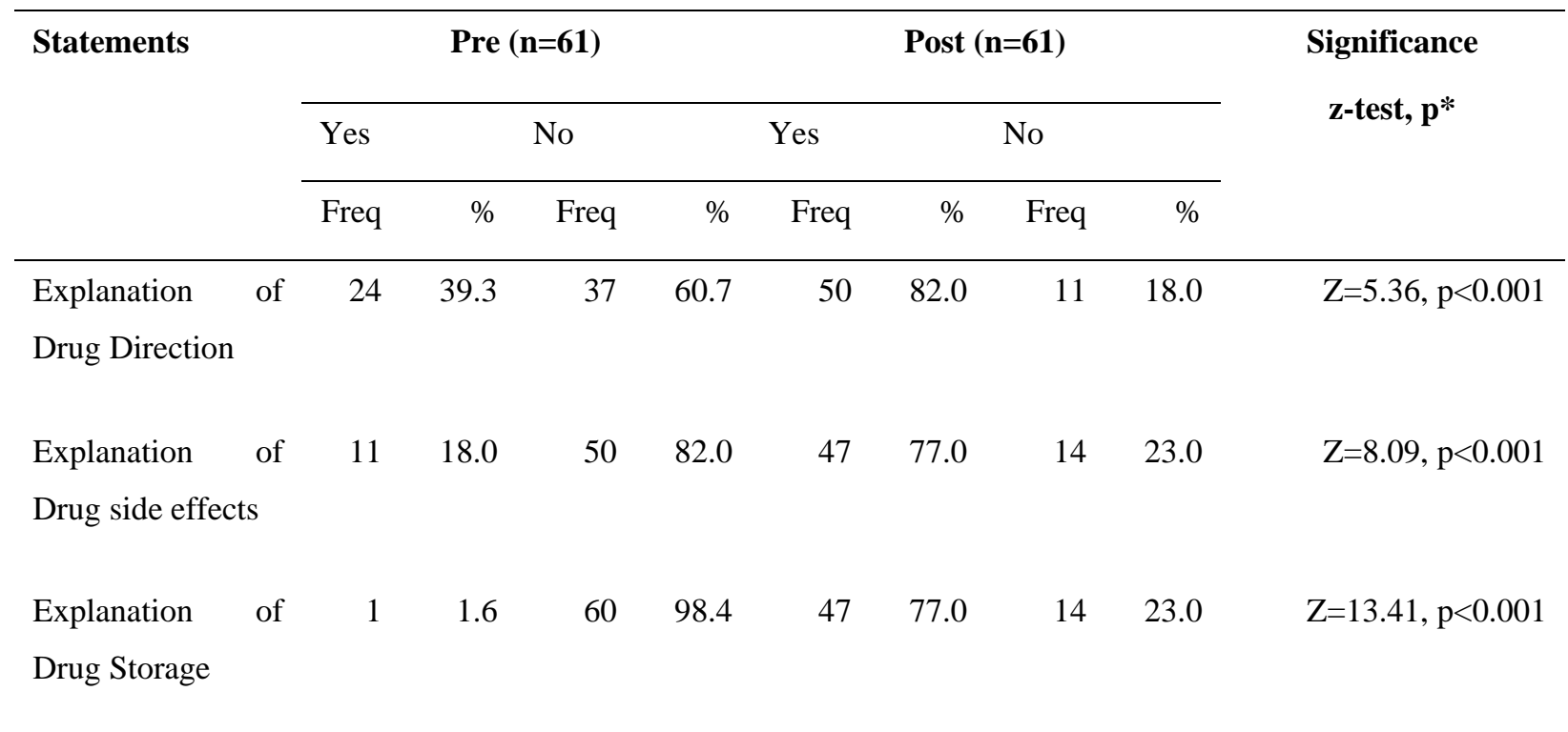

*Difference between two percentages for two proportion tests (z-test) was applied

All the areas of patient education significantly improved after the intervention compared to pre intervention at $\mathrm{p}<0.001$ significance level. Mean satisfaction of patients was measured using a Likert Scale, and satisfaction ranged from 1 (Highly Unsatisfactory) to 5 (Highly Satisfactory). The mean satisfaction was improved from 2.92 to 4.13 at $\mathrm{p}<0.001$ significance level after the intervention (Table 6). The percentage of drugs received by the patients were improved significantly from $83.41 \%$ pre intervention value to $93.97 \%$ post intervention and the $\mathrm{p}$ value was $\mathrm{p}<0.001$ (Table 6). 
Table 6 - Patient satisfaction on drug dispensing and percentage of prescribed drug received before and after the intervention

\begin{tabular}{|c|c|c|c|c|c|c|c|c|c|c|c|c|}
\hline \multirow{2}{*}{ Study areas } & \multirow[t]{2}{*}{$\mathbf{n}$} & \multicolumn{4}{|c|}{ Pre } & \multicolumn{6}{|c|}{ Post } & \multirow{2}{*}{$\begin{array}{r}\text { Significance } \\
(z-\text { test, p) * }\end{array}$} \\
\hline & & Mean & SD & Median & Min & $\operatorname{Max}$ & Mean & SD & Median & Min & $\operatorname{Max}$ & \\
\hline Are you happy about the drug & & & & & & & & & & & & \\
\hline $\begin{array}{l}\text { dispensing by the } \\
\text { pharmacists }\end{array}$ & 61 & 2.92 & 0.78 & 3.00 & 2 & 4 & 4.13 & 0.53 & 4.00 & 3 & 5 & $\mathrm{Z}=7.56, \mathrm{p}<0.001$ \\
\hline
\end{tabular}

* Mann-Whitney U Test was applied 


\section{Drugs stores management practices}

Store management was assessed on all four stores (4) in the hospital based on key selected criteria and they were, percentage of drug balancing, percentage adherence to First In First Out (FIFO) storing method, Thermometer availability at drug stores, Temperature chart maintenance at the drug stores, and cleanliness on all four main drug stores. Three independent observers evaluated the above criteria using a check list and averaged results were documented. The Radar diagram was constructed based on the average results.

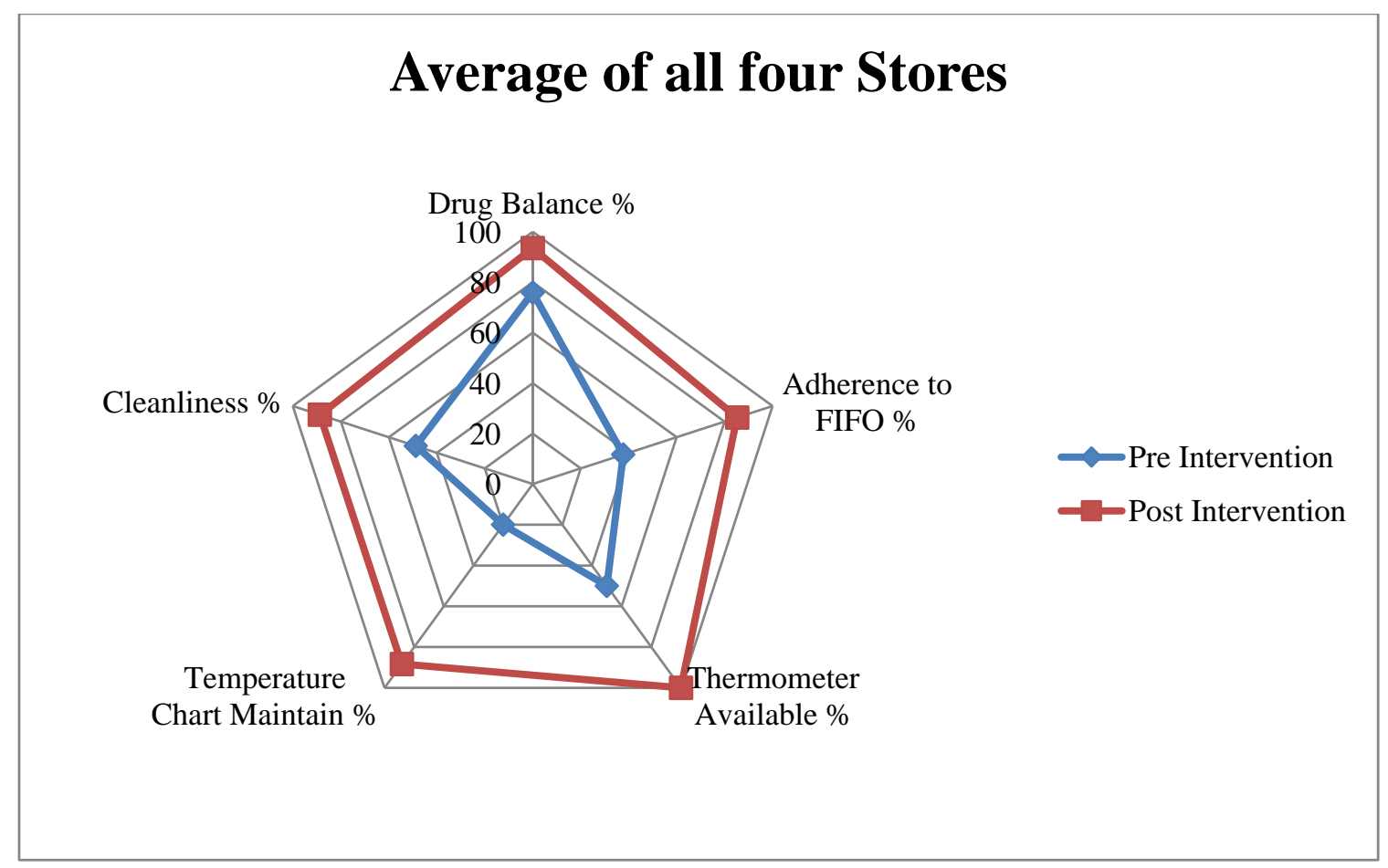

Figure 1 - Radar diagram of pre and post audit status in all 4 stores

The radar diagram (figure 1) visually shows that there is a post intervention improvement in drug balancing, adherence to FIFO, temperature chart maintenance, cleanliness and thermometer availability, when compared to pre intervention level in all four stores. 


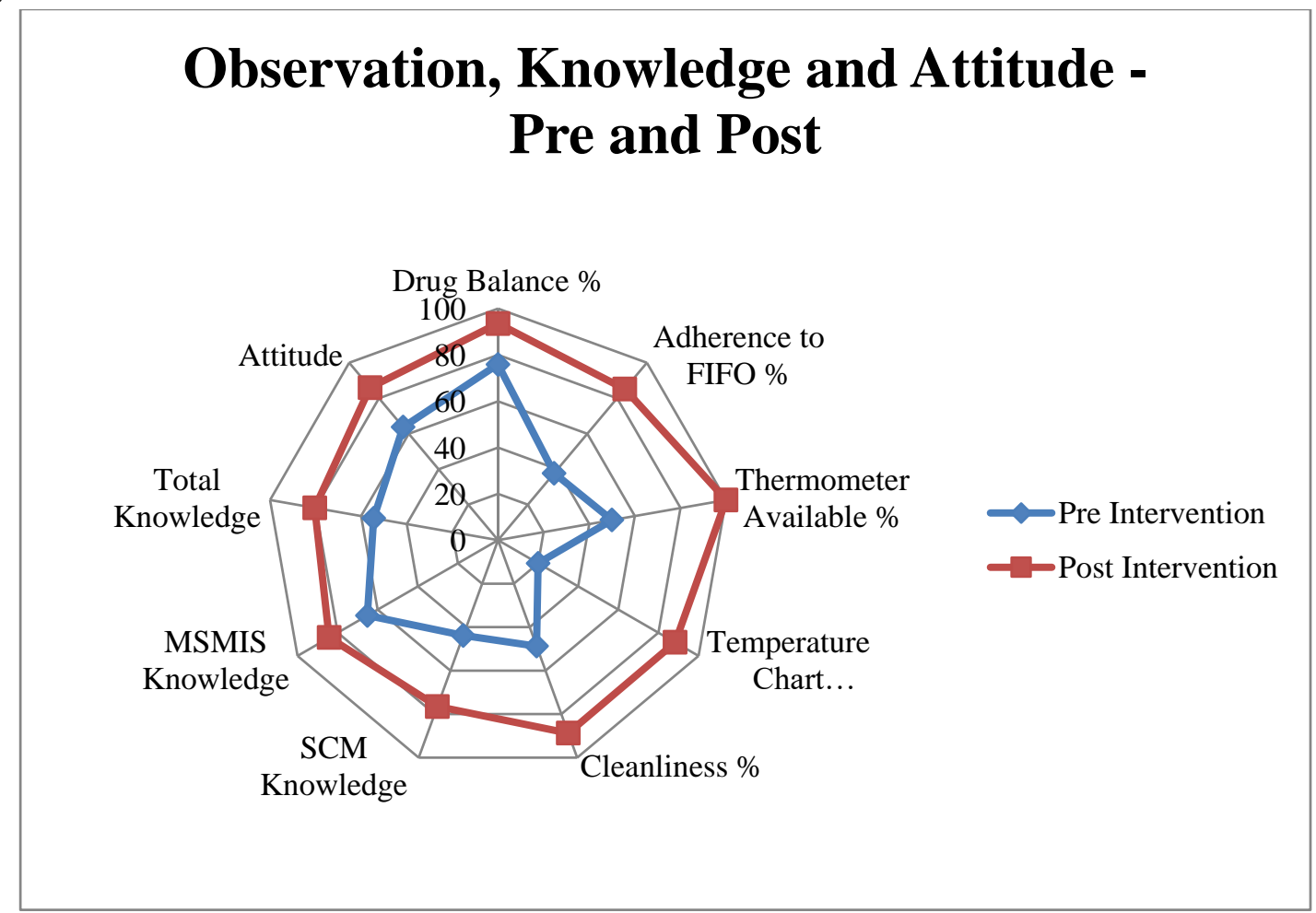

Figure 2 - Radar diagram of Observation and the average knowledge and attitude of the store pharmacists pre and post intervention

Figure 2 visually summarise the knowledge and attitude among the Pharmacists and the store management in a one snapshot. It clearly shows the improvement in Drug Balancing, Adherence to FIFO, Thermometer availability, Temperature Chart Maintenance, Cleanliness in the store, SCM Knowledge, MSMIS Knowledge, Total Knowledge of Drug SCM and the Attitudes, after the intervention among the Pharmacists at CSTH. This shows that improvement of knowledge and attitude have contributed to improvement in drugs stores. 


\section{CONCLUSIONS}

The overall study showed that there is a significant improvement of pharmacists knowledge and attitude on SCM (p < 0.001) by the interventions. There are significant improvements in delays in receiving drugs during last month, out of stock of drugs during last month, delays in local purchase, and the overall satisfaction regarding drug supply to the inwards and units in charges after the interventions. A significant improvement also seen in patient education $(\mathrm{p}<0.001)$, patient satisfaction $(\mathrm{p}<0.001)$ and percentage of receiving drugs at the clinic OPD dispensary $(\mathrm{p}<0.001)$ after the interventions.

Improving the Knowledge and Attitudes on Drug SCM among Pharmacists, is an effective intervention to strengthen the Drug SCM at Institutional Level.

\section{RECOMMENDATIONS}

Similar studies should be carried out at other levels of institutions (Primary care, Secondary care, etc.), to assess and compare the improvement on Knowledge and Attitudes among Pharmacists and the Drugs SCM. By increasing the institution number, increasing the study sample size, using control institutions and additional criterias for assessment will help to validate more and generalize the findings and open up for future researches.

On-line training on SCM should be incorporated into National Health Care system and institutional in-service training programmes for the health care staff who are involved in SCM. Implementation of Online training as a distant learning method is a cost-effective method for health care human resource trainings.

It is recommended to conduct regular capacity building programmes in health care institutions which will help staff to perform better and thereby increase the institutional performance.

\section{REFERENCES}

1. Mentzer JT, DeWitt W, Keebler JS, Min S, Nix NW, Smith CD, et al. DEFINING SUPPLY CHAIN MANAGEMENT. J Bus Logist [Internet]. 2001 Sep 1 [cited 2019 Mar 27];22(2):1-25. Available from: http://doi.wiley.com/10.1002/j.21581592.2001.tb00001.x

2. Ayers JB. Handbook of supply chain management. St. Lucie/APICS Series on Resource Management, New York.; 2001.

3. Clark M, Barraclough A. MANAGING MEDICINES AND HEALTH PRODUCTS CHAPTER 8 OF HEALTH SYSTEMS IN ACTION [Internet]. Management Sciences for Health; 2010 [cited 2017 Sep 27]. Available from: http://apps.who.int/medicinedocs/documents/s22123en/s22123en.pdf

4. Javid Iqbal M, Geer MI, Dar A. Medicines Management in Hospitals: A Supply Chain Perspective A multifaceted Review journal in the field of Pharmacy. Syst Rev Pharm [Internet]. 2018 [cited 2017 Sep 27];8. Available from: http://www.sysrevpharm.org/sites/default/files/10.5530.srp_.2017.1.14.pdf

5. Ministry of Health Nutrition and Indigenous Medicine. Annual Health Bulletin 2016. Medical Statistics Unit Ministry of Health, Nutrition and Indigenous Medicine Sri Lanka; 2018. 
6. Avinash Verma Rp. Role of Pharmacist in Supply Chain, Logistics \&amp; Storage of Medicine. [Internet]. 2018 [cited 2019 Mar 27]. Available from: https://www.linkedin.com/pulse/role-pharmacist-supply-chain-logistics-storage-avinashverma-rph

7. WHO Regional Office for Africa. Management of Drugs at Health Centre Level [Internet]. World Health Organization Regional Office for Africa; 2004 [cited 2017 Sep 27]. Available from: http://apps.who.int/medicinedocs/pdf/s7919e/s7919e.pdf

8. International Pharmaceutical Federation. Pharmacists in the Supply Chain: The Role of the Medicines Expert in Ensuring Quality and Availability, 2018. International Pharmaceutical Federation (Fip) [Internet]. Essential Medicines and Health Products Information Portal A World Health Organization resource. 2018 [cited 2019 Mar 27]. Available from: http://apps.who.int/medicinedocs/en/m/abstract/Js23434en/

9. Pérez-Salazar M del R, Aguilar Lasserre AA, Cedillo-Campos MG, Hernández González JC. The role of knowledge management in supply chain management: A literature review. J Ind Eng Manag [Internet]. 2017 Oct 26 [cited 2019 Jun 28];10(4):711. Available from: http://www.jiem.org/index.php/jiem/article/view/2144

10. Monica Balakrishnan Kokilam1, Harish Ganesh Joshi1, Veena Ganesh Kamath. Assessment of Pharmaceutical Store and Inventory Management in Rural Public Health Facilities-A study with reference to Udupi District, Karnataka. Pharm Methods [Internet]. 2015 [cited 2019 Apr 25];6(2):53-9. Available from: www.phmethods.net 